\title{
EGGSHELL COMPOSITION OF SQUAMATE REPTILES: RELATIONSHIP BETWEEN EGGSHELL PERMEABILITY AND AMINO ACID DISTRIBUTION
}

\author{
OWEN J. SEXTON, ${ }^{1, *}$ JUDITH E. BRAMBLE, ${ }^{2}$ I. LORRAINE HEISLER, ${ }^{3}$ \\ CHRISTOPHER A. PHILLIPS, ${ }^{4}$ and DAVID L. COX ${ }^{5}$ \\ ${ }^{1}$ Department of Biology and Tyson Research Center, Washington University, P.O. Box 258, \\ Eureka, MO 63025, USA \\ ${ }^{2}$ Environmental Science Program, DePaul University, 124 McGowan Center, \\ 2325 N. Clifton Avenue, Chicago, IL 60614, USA \\ ${ }^{3}$ South Florida Ecological Services Office, United States Fish and Wildlife Service, \\ 1339 20th Street, Vero Beach, FL 32960, USA \\ ${ }^{4}$ Center for Biodiversity, Illinois Natural History Survey, 607 E. Peabody Dr., Champaign, \\ IL 61820, USA \\ ${ }^{5} 9495$ Periwinkle Dr., Vero Beach, FL 32963, USA
}

(Received February 9, 2005; revised May 10, 2005; accepted June 15, 2005)

\begin{abstract}
Most snakes and lizards produce eggs with flexible shells that interact with the environment to maintain water balance. Geckos produce rigid eggshells that are independent of an external source of water and can be oviposited in more open, dryer locations. In this study, we analyzed and compared the amino acid composition of 24 lizard species, six snake species, and four outgroups (including avian and reptilian elastin and chicken eggshell). Rigid Gecko eggshells had significantly lower levels of seven of the 17 amino acids evaluated. Multivariate analysis showed that proline was the most important amino acid in distinguishing between these two groups of eggshells, occurring at significantly higher levels in flexible eggshells. High levels of proline have also been observed in the eggshells of other species. Proline and other amino acids are associated with the alleviation of water and salt stress in plants.
\end{abstract}

Key Words-Amino acid analysis, eggshells, squamate reptiles, proline, water relations, water-soil relations.

* To whom correspondence should be addressed. E-mail: sexton@biology.wustl.edu 


\section{INTRODUCTION}

Most species of squamate reptiles (lizards and snakes) are oviparous (Pianka and Vitt, 2003). Packard et al. (1982) have demonstrated that there are two types of squamate eggshells: flexible and rigid. Females of oviparous species with flexible eggshells deposit the eggs in nests in the soil or in organic debris, which serves as a source of the water necessary for successful development (Tracy, 1980; Packard et al., 1982). The passage of water from the surrounding medium through the eggshell and into the interior of the egg can be bidirectional, depending upon hydric dynamics (Sexton et al., 1979; Andrews and Sexton, 1981). In contrast, the eggs of those species with rigid eggshells are independent of an external source of water and can be oviposited in relatively open, dry locations (Sexton and Turner, 1970; Pianka and Vitt, 2003).

Krampitz et al. (1972) determined the amino acid composition of eggshells of some reptiles and birds and proposed that analyses of the amino acid composition of those eggshells represented "a basis for heterogeneously structured proteins which might be class-dependent if not even speciesspecific." Later, Kriesten (1975) determined that the flexible eggshells of the lizard Iguana iguana contained high levels of the amino acid proline. His finding was confirmed by Cox et al. $(1982,1984)$.

In this work, we will expand the scope of these earlier studies by surveying the relative abundance of the amino acids in the eggshells of a variety of oviparous squamate reptiles to determine what role they, and in particular proline, might play in the dynamics of water transfer between soil and egg from oviposition to hatching. We will demonstrate that there is a distinct difference between the amino acid composition of flexible vs. rigid eggshells. We will also briefly review the literature about the relationship between amino acid content and the hydric environment of other disparate taxa.

\section{METHODS AND MATERIALS}

Sample Collections. We examined the eggshells of 24 species of lizards of seven families and of six species of snakes in three families (Table 1). We obtained eggs collected in nature or from eggs oviposited by captive females. The geographic range of the species are: the United States of America, the Republic of Panama, Australia, northern Africa, southern Asia, Pacific atolls, the Galapagos Islands, and Caribbean Islands.

Procedure. Eggshell samples for amino acid samples were obtained by cutting 5-mm sections from each whole, air-dried shell. Samples were weighed, washed in distilled water, and hydrolyzed in constant boiling $\mathrm{HCL}$ at $105^{\circ} \mathrm{C}$ for $24 \mathrm{hr}$. We then dried the samples using a Speed Vac concentrator. We 
determined the amino acid composition of each sample using a Beckman 119C analyzer with a program optimized for resolving elastin crosslinking amino acids (Mecham and Lange, 1982). We performed triplicate analyses on each sample. We selected the extracellular, fibrous proline-rich proteins, reptilian elastin and keratin (Sage and Gray, 1979), and avian elastin (Foster et al., 1975) as controls as well as chicken eggshell (Leach et al., 1981), because of the proteinacious, fibrous nature of reptile eggshells (Sexton et al., 1979; Cox et al., 1982; Packard et al., 1982; De-Salle et al., 1984; Heulin, 1990).

Statistical Analysis. We used Nei's index of genetic similarity (Nei, 1972) to compare pairs of samples. We employed $t$-tests to evaluate individual amino acids and multivariate tests to examine sets of amino acids. Discriminant function analysis was used to identify which set of amino acids best separated the various squamate taxa. Factor analysis was used to examine the relationships among amino acids to identify a smaller set of composite variables (factors), which were then used to examine differences among the squamate groups. In all cases, overall test alphas were maintained at $P=0.05$; all tests were two-tailed. When several individual analyses (e.g., $t$-tests on each amino acid) were performed, the individual test alphas were divided by the number of comparisons (the Bonferroni adjustment) to conserve an overall alpha of 0.05. The statistical tests chosen assume that the character traits of taxa are independent. Because of phylogenetic relationships, this is likely not to be true, and so type 1 errors are likely to be inflated (Garland et al., 1993). The impact of phylogenetic relationship is addressed in the discussion.

\section{RESULTS}

Proline was the most abundant amino acid of the 17 amino acids examined for 29 of the 30 species of squamate eggshells although there was considerable variation among taxa (Table 1). Such variation could result from genetic or environmental factors. To determine if differences in eggshell composition have a genetic component, we compared the overall similarity of pairs of congeneric species with pairs of more distantly related species with the expectation that more closely related species would be more similar than more distantly related ones. In addition, if eggshell composition is largely genetically determined, then sets of species with similar diets should not be different from sets of comparisons of species with different diets. For this analysis, we used all species within the same family that differed at a relatively gross level of diet similarity, comparing within and between herbivorous and carnivorous species.

From the available data, there were five possible comparisons we could make between pairs of species within the same genus (three species of 


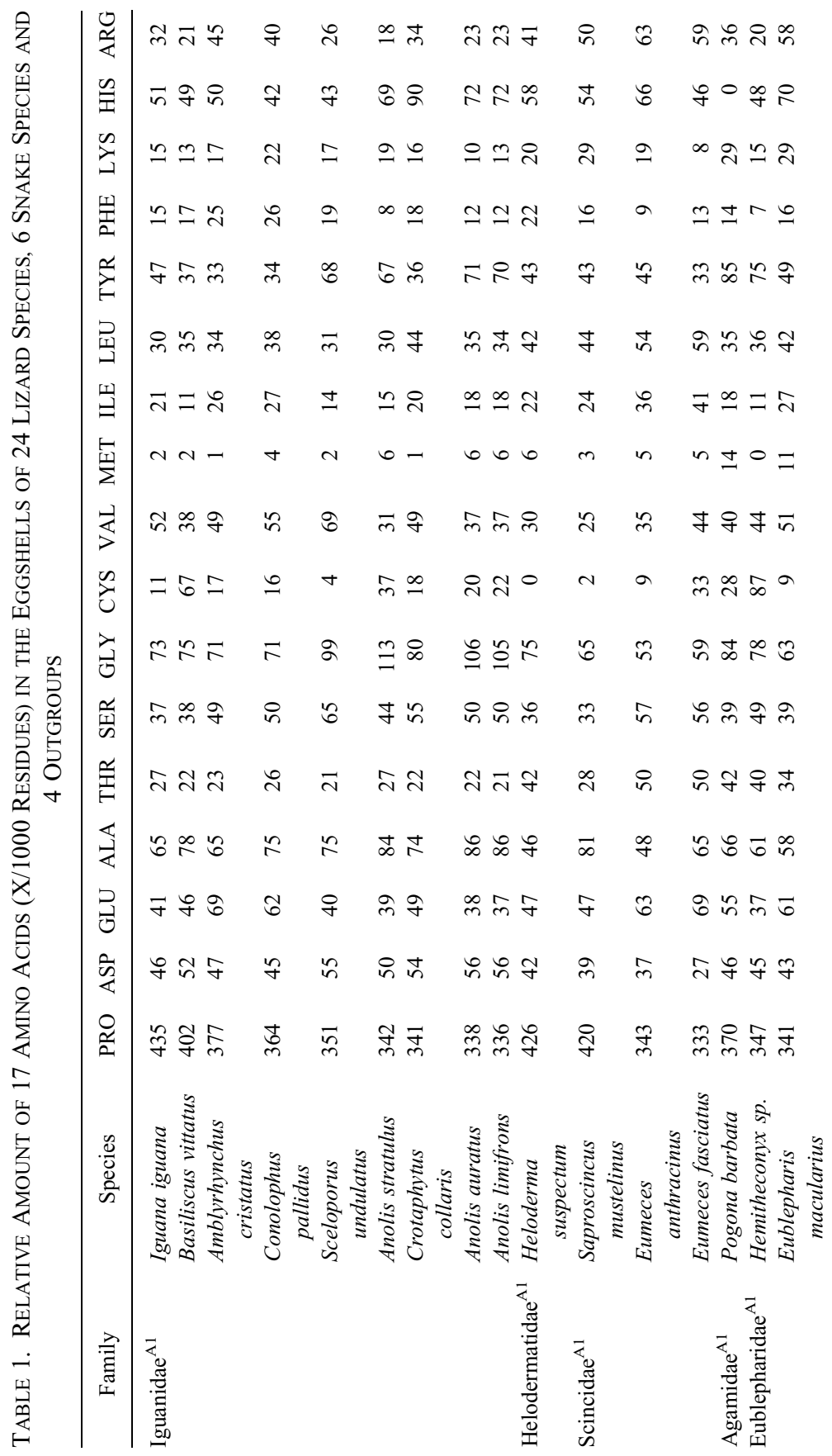




\begin{tabular}{|c|c|c|c|c|c|c|c|c|}
\hline 6 & $m$ & ケ & 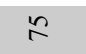 & $\ddot{m} \stackrel{\infty}{-}$ & $\stackrel{\infty}{m}$ & $\infty \underset{\sim}{\infty}$ & ป⿻一 & $\vec{\pi}$ \\
\hline & $\hat{n}$ & チำ & i & $\approx \widetilde{\sigma}$ & 8 & in in $\infty$ & $n \tilde{n}+0 m n$ & $=$ \\
\hline & $\vec{\sim}$ & $\infty$ オீ & i & ¿ ণ & 6 & $\infty \circ=$ & $\therefore \simeq r+\not m$ & 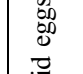 \\
\hline & $\simeq$ & $=2 \infty$ & $\infty$ & $\Xi ニ$ & $\cong$ & $ㄷ ㅇ$ & 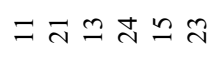 & 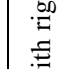 \\
\hline & $n$ & $\hat{\sim} \pm \stackrel{\infty}{N}$ & $m$ & $\pm \cong$ & r & $\stackrel{\wp}{+} \bar{\sim}$ & 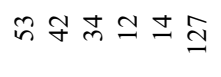 & \\
\hline & $\vec{m}$ & ஜำ & 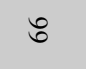 & $\stackrel{\infty}{+}$ & $\bar{m}$ & ढ्ले ले ले & 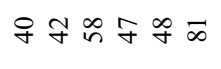 & \\
\hline & $\vec{\sim}$ & तั & $\stackrel{\sim}{\sim}$ & సิ ลิ & $\because$ & $\cong \cong$ & $\dot{\sim} \curvearrowleft ニ \Omega$ & \\
\hline & $\circ$ & $m+n$ & N & in in & $r$ & $\infty 60$ & onno O - & 0 \\
\hline & $\vec{n}$ & 요 m & $\dddot{r}$ & テ & ర్ & 8 ถึก & 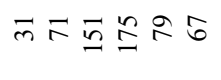 & $\ddot{z}$ \\
\hline & $\simeq$ & 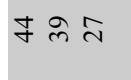 & ㅇ & $n \infty$ & 于 & 능 & f $0-0 g i n$ & 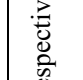 \\
\hline & 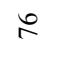 & $\infty$ ํㅡ & J & $\cong \hat{0}$ & 8 & 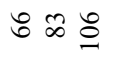 & 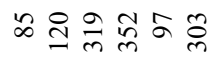 & 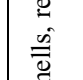 \\
\hline & ల & ஃ ป & $\bar{\infty}$ & ๖ำ & \& & 守会8 & $\stackrel{\infty}{+}=$ 的 8 in & की \\
\hline & $\stackrel{\infty}{m}$ & ప $\lesssim \infty$ & $\pi$ & $\vdash 2$ & $\stackrel{\infty}{m}$ & $n$ n & 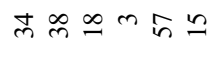 & $x$ \\
\hline & $\approx$ & สุळ & $\hat{\infty}$ & के & f & 6 in & 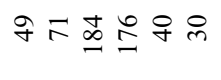 & 3 \\
\hline & อ & สิ ฮิ in & J & ลㅇ & $\hat{n}$ & $\stackrel{6}{6}$ & 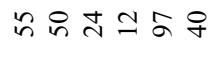 & एँ \\
\hline & ร & 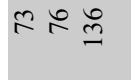 & $\hat{\sigma}$ & ホஃ & $m$ & ஸ & గ్ర & $\bar{n}$ \\
\hline & $\stackrel{?}{\mathrm{~m}}$ & $\stackrel{\infty}{\simeq} \underset{\beth}{=} \stackrel{\infty}{=}$ & $\stackrel{+}{\stackrel{2}{2}}$ & せั こ & $\underset{\infty}{+\infty}$ & लై సి సి & 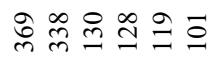 & ర্] \\
\hline 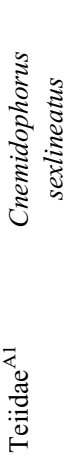 & 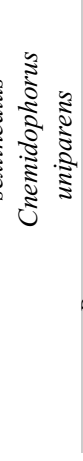 & 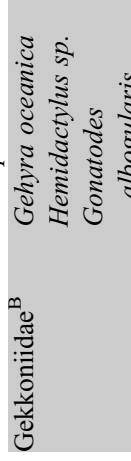 & 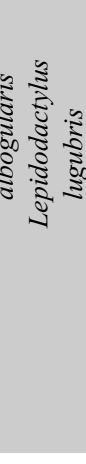 & 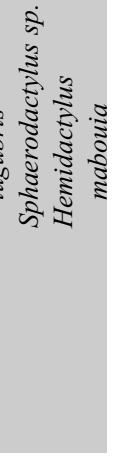 & 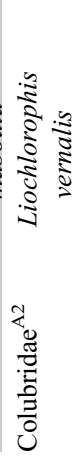 & 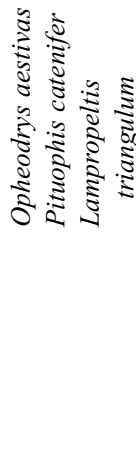 & 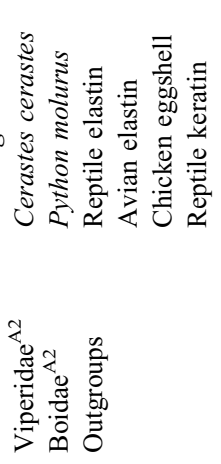 & 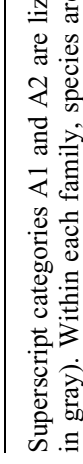 \\
\hline
\end{tabular}


Anolis providing three comparisons, and two species each of Eumeces and Cnemidophorus, each providing a single paired comparison). We then randomly chose five pairwise comparisons of species from different genera within the same family. Pairs of congeneric species were significantly more similar to each other than were pairs of other confamilial species (Nei's $I=0.995$ vs. $0.976 ; t=3.06$, $d f=8, P=0.016)$, providing evidence that variation in eggshell composition has a significant genetic component.

Within the iguanid lizards, three species, I. iguana, Amblyrhynchus cristatus, and Conolophus pallidus, are primarily vegetarian, providing three pairwise comparisons. The remaining six species of iguanids largely eat an animal diet. To maintain the same level of taxonomic relationship, we used only one species of Anolis (A. stratulus), which provided a total of four iguanid species for six pairwise comparisons. Vegetarian species had eggshell amino

Table 2. Means \pm SE for Each Amino Acid and the First Five Principle COMPONENTS FOR LiZARDS WITH FLEXIBLE SHELlS AND GEKKONID LIZARDS WITH HARD SHELLS

\begin{tabular}{|c|c|c|c|c|c|}
\hline \multirow{2}{*}{$\begin{array}{c}\text { Shell } \\
\text { Variable }\end{array}$} & \multirow{2}{*}{$\frac{\text { Lizards with flexible shells }}{N=18}$} & \multirow{2}{*}{$\frac{\text { Lizards with hard shells }}{N=6}$} & \multicolumn{3}{|c|}{$t$-Test for equality of means } \\
\hline & & & $t$ & $d f$ & $P$ (two-tailed) \\
\hline PRO & $\mathbf{3 6 3 . 8} \pm 8.01$ & $\mathbf{1 4 0 . 8} \pm 7.82$ & 15.13 & 22 & $<0.001$ \\
\hline TYR & $\mathbf{5 2 . 3} \pm 3.89$ & $21.7 \pm 3.83$ & 4.27 & 22 & $<0.001$ \\
\hline ASP & $45.6 \pm 1.82$ & $\mathbf{8 4 . 3} \pm 10.51$ & -5.87 & 22 & $<0.001$ \\
\hline THR & $32.4 \pm 2.50$ & $\mathbf{8 1 . 6} \pm 2.85$ & -10.54 & 22 & $<0.001$ \\
\hline SER & $46.3 \pm 2.11$ & $\mathbf{1 0 0 . 5} \pm 8.21$ & -9.26 & 22 & $<0.001$ \\
\hline GLU & $\mathbf{5 1 . 9} \pm 2.88$ & $\mathbf{9 3 . 7} \pm 7.38$ & -6.43 & 22 & $<0.001$ \\
\hline LEU & $\mathbf{3 9 . 3} \pm 2.08$ & $\mathbf{6 0 . 9} \pm 7.25$ & -3.99 & 22 & $<0.001$ \\
\hline LYS & $18.3 \pm 1.43$ & $26.1 \pm 4.08$ & -2.32 & 22 & 0.030 \\
\hline GLY & $78.1 \pm 4.05$ & $94.1 \pm 6.77$ & -1.99 & 22 & 0.059 \\
\hline ALA & $69.1 \pm 2.87$ & $77.7 \pm 9.24$ & -1.20 & 22 & 0.242 \\
\hline CYS & $22.1 \pm 5.33$ & $37.1 \pm 2.37$ & -1.59 & 22 & 0.127 \\
\hline VAL & $42.7 \pm 2.57$ & $39.5 \pm 2.06$ & 0.69 & 22 & 0.496 \\
\hline MET & $4.9 \pm 0.90$ & $3.9 \pm 0.54$ & 0.65 & 22 & 0.520 \\
\hline ILE & $22.4 \pm 2.01$ & $25.8 \pm 1.65$ & -0.92 & 22 & 0.370 \\
\hline PHE & $15.0 \pm 1.28$ & $16.7 \pm 1.23$ & -0.72 & 22 & 0.479 \\
\hline HIS & $55.2 \pm 4.41$ & $56.4 \pm 6.73$ & -0.14 & 22 & 0.888 \\
\hline ARG & $37.9 \pm 3.56$ & $38.3 \pm 8.17$ & -0.05 & 22 & 0.962 \\
\hline Factor 1 & $\mathbf{0 . 1 2} \pm 0.092$ & $-\mathbf{1 . 3 2} \pm 0.162$ & -7.83 & 22 & $<0.001$ \\
\hline Factor 2 & $\mathbf{0 . 5 8} \pm 0.079$ & $-\mathbf{1 . 2 2} \pm 0.081$ & -12.29 & 22 & $<0.001$ \\
\hline Factor 3 & $-0.37 \pm 0.254$ & $0.50 \pm 0.326$ & 1.81 & 22 & 0.084 \\
\hline Factor 4 & $0.14 \pm 0.171$ & $0.73 \pm .228$ & 1.81 & 22 & 0.085 \\
\hline Factor 5 & $0.04 \pm 0.092$ & $-0.23 \pm 0.320$ & -1.14 & 22 & 0.265 \\
\hline
\end{tabular}

Values in bold significantly differ between the two groups of lizards. 
acid compositions more similar to each other than did carnivorous species. The nine paired comparisons of species with similar diets were not significantly different from the 12 paired comparisons of species with different diets $(t=$ $0.835 ; d f=19 ; P=0.41$ ), suggesting that diet is not a significant determinant of differences in eggshell composition.

The key question is whether eggshell composition differs between squamates with flexible vs. hard-shelled eggs. Relative concentrations of seven of the 17 amino acids differed significantly between geckos and the other squamates when individually compared (Table 2). Factor analysis reduced the 17 amino acids to five principal components (Factors), which accounted for $80.8 \%$ of the original variation. Both of the first two factors, which together accounted for $53.2 \%$ of the variation, differed significantly between geckos and the other lizard taxa (Table 2). Graphing Factor 1 against Factor 2 shows how each separates the two groups of lizards (Figure 1). Snakes are interspersed with the

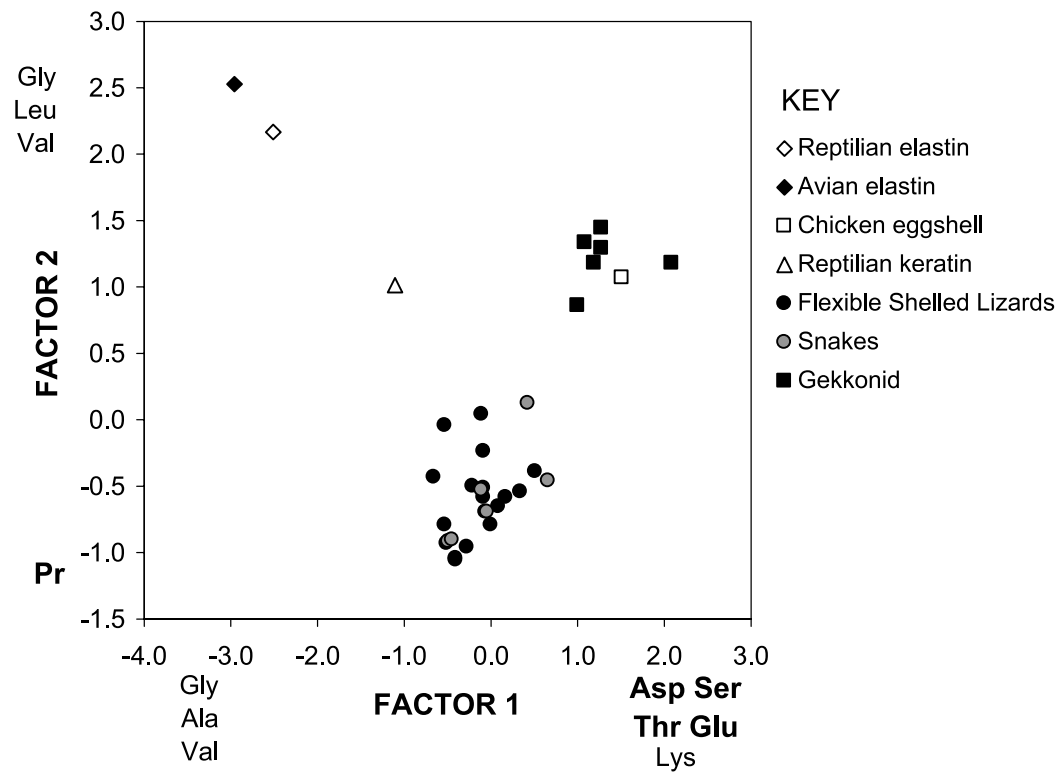

FIG. 1. Clustering of samples by factor analysis. The variables that load highest in Factor 1 are aspartic acid, serine, threonine, and glutamic acid, all of which are positively associated with Factor 1. The variable that loads highest in Factor 2 is proline and it is negatively associated with Factor 2. Variables that are more weakly correlated are included (but not in bold), and whether they are positively or negatively associated is indicated by their placement on the axis. Both factors clearly separate the flexible shelled lizards and snakes from the Geckos, although Factor 2 shows the better separation. 
flexible-shelled lizards and, interestingly, the chicken eggshell nests with the hard-shelled geckos. The variables that load highest in Factor 1 are threonine, glutamic acid, aspartic acid, and serine (loading values: 0.85, 0.83, 0.81, and 0.78 , respectively). Rigid eggshells are associated with high levels, flexible eggshells with lower values. The variable that loads highest in Factor 2 is proline (loading value, -0.91 ). High values of factor 2 are associated with flexible eggshells, lower values with rigid eggshells.

Stepwise discriminant function was used to determine which set of amino acids can best be used to separate the geckos from the flexible egg-shelled lizards. Proline, by itself, accounted for $90.8 \%$ of the differences between these two groups. Threonine, isoleucine, and phenylalanine significantly contributed to discrimination between the two groups, but together added less than $5 \%$ to the model. The best discriminant function $(-4.193+0.028 *$ Pro $+0.092 *$ Ile $\left.0.098 \mathrm{Thr}-0.143^{*} \mathrm{Phe}\right)$ effectively separates members of these two groups. When the discriminant function is applied to the snakes, it places them all in the flexible-shelled lizards. When the equation is applied to the outgroups, it places the two elastin samples (reptile and avian) with the lizards and the chicken eggshell and reptilian keratin with the hard-shelled geckos.

\section{DISCUSSION}

We have clearly demonstrated that the amino acid composition of the eggshells of 24 species of flexible shelled squamate reptiles from nine different families differs from that of the six species of rigid-shelled geckos (Figure 1). Eggshell composition was shown to have a significant genetic composition, and, thus, it is possible that the differences observed are due to genetic relatedness and not to environmental adaptation. Recent phylogenetic analysis of the squamate reptiles places the Gekkoniidae and the Eublepharidae in a clade distinct from other squamates (Townsend et al., 2004). The eggshells of the two species of Eublepharidae in this study cluster with the other flexible shelled squamates and not with the more closely related Gekkoniidae. In addition, the clustering of the chicken eggshell with the rigid-shelled Geckos argues further that the differences observed in eggshell composition is an adaptation and not an artifact of common ancestry. The placement of snakes, all with flexible eggshells, within the flexible shelled lizards is consistent with both an adaptive explanation (all have flexible eggshells) and a phylogenetic one (see Townsend et al., 2004).

The eggs of some squamate species with flexible eggshells (e.g., Sceloporus scalaris and $S$. virgatus) can gain two to four times their mass through the influx of water from the surrounding medium (Andrews, 1997). 
Proline, the predominant amino acid of pliable eggshells, is hydrophobic, and proline-rich sequences generally form extended structures and flexible regions that are hard to crystallize (Williams, 1994). During early external development of the egg, the inner surface of the eggshell first becomes covered by the yolk sac and later by the chorio-allantoic membrane (Andrews, 2004; Ackerman and Lott, 2004). Andrews (1997) has demonstrated that in S. scalaris and S. virgatus (members of the flexible eggshell group of squamates) much of the water influx during the incubation period occurs through the chorio-allantoic membrane. Hence, the eggshell serves as a porous, flexible barrier between the environment and the embryo with its associated embryonic membranes.

The presence of high levels of proline is not restricted to squamate eggshells. High levels have been reported from egg capsules of the skate, Raja erinacea (Cox et al., 1987), and from the eggshell of Drosophila melanogaster (Gigliotti et al., 1989; Waring et al., 1990). Proline also serves a conspicuous role in the alleviation of water and salt stress in plants (Larcher, 2003; di Toppi and Pawlik-Skowronska, 2003). Many species of plants, faced with drought or an excess of salt in the external environment, induce the synthesis of proline in the root system, and this serves as a protectant against negative hydric changes in the external environment (Kuznetsov and Shevyakova, 1999; de Ronde et al., 2000; Ramanjulu and Sudhakar, 2000).

Although the rigid eggshells of geckos contain lesser amounts of proline than flexible eggshells, they do contain higher levels of four other amino acids (Table 2). Of these four, aspartic acid/asparagine (ASX) and glutamic acid/ glutamine (GLX) have been observed to accumulate in some plant species as nonspecific reactions to salt stress (Larcher, 2003). The high levels of these two amino acids in gecko eggshells may play an analogous role and may have indirectly played a role in accounting for the wide distribution of some species of geckos in the islands of the South Seas (Pianka and Vitt, 2003). The thesis is that gecko eggs, deposited on trees that were later blown into the sea, could have been transported by wind and wave to islands lacking that particular species, thus establishing a new colony.

These findings have further implications for: (1) the study of eggshell morphology of a variety of animals, (2) biochemical dynamics involved in hydric relationships between a wide variety of organisms and their environment, and (3) evolutionary relationships of various taxa.

Acknowledgments - This project was initiated under the auspices of a fellowship to OJS from the Dept. of Zoology, University of New England, Armidale, N.S.W., Australia, in the fall of 1984. Prof. Harold Heatwole and Audrey Heatwole provided basic support and guidance; Drs. Menna Jones and Jeff Miller aided the field work. The Smithsonian Tropical Research Institute in the Republic of Panama offered physical and intellectual support with special assistance provided by Dr. A. Stanley Rand. The Herpetarium of the St. Louis Zoo, St. Louis, MO, USA, provided eggshells of many species. Dr. Brian E. Viets provided us with eggshells of Hemitheconyx and 
Dr. David Crews with Cnemidophorus uniparens. Many eggshells were obtained from the St. Louis area, particularly at the Washington University Tyson Research Center (Dr. Richard Coles, Director). Collecting in Missouri was carried out under a collecting permit from the Missouri Dept. of Conservation. Profs. Oscar Chilson, Daniel Kohl, and Robert Thach kindly reviewed early versions of this article, and two journal reviewers offered salient and helpful comments.

\section{REFERENCES}

ACKERMAN, R. A. and LOTT, B. 2004. Thermal, hydric and respiratory climate of nests, pp. 15-43, in D. C. Deeming (ed.). Reptilian Incubation: Environment, Evolution and Behaviour. Nottingham University Press, Nottingham, Great Britain.

ANDREWS, R. M. 1997. Evolution of viviparity: variation between two sceloporine lizards in the ability to extend egg retention. J. Zool. 250:579-595.

ANDREwS, R. M. 2004. Patterns of Embryonic Development, pp. 75-102, in D.C. Deeming (ed.). Reptilian Incubation: Environment, Evolution and Behaviour. Nottingham University Press, Nottingham, Great Britain.

ANDREws, R. M. and SEXTON, O. J. 1981. Water relations of the eggs of Anolis auratus and Anolis limifrons. Ecology 62:556-562.

Cox, D. L., Mecham, R. P., and SeXton, O. J. 1982. Lysine derived cross links are present in an non-elastin proline-rich protein fraction of Iguana iguana eggshell. Comp. Biochem. Physiol. 72:619-624.

Cox, D. L., Mecham, R. P., Коов, R. J., and Sexton, O. J. 1984. External incubation alters the composition of squamate egg-shells. Comp. Biochem. Physiol. B. 79:481-488.

Cox, D. L., Mecham, R. P., and KoOB, R. J. 1987. Site specific variation in amino acid composition of skate capsules Raja erinacea mitchelli 1825. J. Exp. Mar. Biol. Ecol. 107:71-74.

De Ronde, J. A., Spreeth, M. H., and Cress, W. A. 2000. Effect of antisense L-DELTA1pyrroline-5-carboxylate reductase transgenic soybean plants subjected to osmotic and drought stress. J. Plant Growth Regul. 32:13-26.

De-Salle, R., Veith, G. M., and SeXton, O. J. 1984. An enzymatic and histochemical analysis of eggshells of anoline lizards. Comp. Biochem. Physiol. 78:237-242.

Di TopPI, L. S. and Pawlik-Skowonska, B. 2003. Abiotic Stresses in Plants. Kluwer Academic Publishers, Dordrecht.

Foster, J. A., Shapiro, B., Voynow, P., Crombie, G., Faris, B., and Franzblau, C. 1975. Isolation of soluble elastin from lathrytic chicks. Comparison to tropoelastin from copper deficient pigs. Biochemistry 14:5343-5346.

Garland, G., Dickerman, A. W., Janis, C. M., and Jones, J. A. 1993. Phylogenetic analysis of covariance by computer simulation. Syst. Biol. 42:265-292.

Gigliotti, S., Graziani, F., De-Ponti, L., Rafti, F., Manzi, A., Lavorgna, G., Gargiulo, G., and MALVA, C. 1989. Sex-specific tissue-specific and stage-specific expression of a vitelline membrane protein gene from region 32 of the second chromosome of Drosophila melanogaster. Dev. Genet. 10:33-41.

Heulin, B. 1990. Etude comparative de la membrane coquillière chez les souches ovipares et vivipares de Lacerta vivipara. Can J. Zool. 68:1015-1019.

KrampitZ, G., ERBEN, H. K., and Kriestan, K. 1972. Ueber Aminosaeurenzusammensetzung und Struktur von Eischalen. Biomineralization 4:87-99.

KRIESTEN, K. 1975. Untersuchungen ueber Ultrastruktur, Proteinmuster und AminosaeurenZusammensetzung der Eischalen von Testudo elaphantopus, Caiman crocodilus und Iguana iguana. Zool. Jahrb. Anat. 94:101-122. 
Kuznetsov, V. V. and Shevyakova, N. I. 1999. Proline under stress: biological role, metabolism and regulation. Russian J. Plant Phys. 46:274-287. (English Translation)

LARCHER, W. 2003. Physiological Plant Ecology, pp. 1-513. Springer, Berlin.

LEACH, R. M., RUCKER, R. B., and VAN DYKE, G. P. 1981. Eggshell membrane protein: a nonelastin desmosine/isodesmosine containing protein. Arch. Biochem. Biophys. 207:353-359.

MeCHAM, R. P. and LANGE, G. 1982. Antigenicity of elastin: characterization of major antigenic determinants on purified insoluble elastin. Biochemistry 21:669-675.

NEI, M. 1972. Genetic distance between populations. Am. Nat. 106:283-292.

Packard, M., PaCKard, G. C., and BoARdman, T. J. 1982. Structure of eggshells and water relations of reptilian eggs. Herpetologica 38:136-155.

PiankA, E. and ViTT, L. J. 2003. Lizards, Windows to the Evolution of Diversity. University of California Press, Berkeley, CA.

Ramanjulu, S. and SudhaKar, C. 2000. Proline metabolism during hydration in two mulberry genotypes with contrasting drought tolerance. J. Plant Phys. 157:81-85.

Sage, H. and Gray, W. R. 1979. Studies on the evolution of elastin-I. Phylogenetic distribution. Comp. Biochem. Physiol. 64B:313-327.

SEXTON, O. J. and TURNER, O. 1970. The reproductive cycle of a tropical lizard. Ecology $52: 159-164$.

Sexton, O. J., Veith, G. M., and Phillips, D. M. 1979. Ultrastructure of the eggshell of two species of Anoline lizards. J. Exp. Zool. 207:227-236.

Townsend, T. M., Larson, A., Louis, E., and MaceY, J. R. 2004. Molecular phylogenetics of Squamata: The position of snakes, Amphisbaenians and Dibamids, and the rood of the Squamate tree. Syst. Biol. 53:735-757.

TRACY, C. R. 1980. Water relations of parchment-shelled lizard (Sceloporus undulatus) eggs. Copeia 1980:478-482.

WARING, G. L, HAWLEY, R. J., and SCHOENFELD, T. 1990. Multiple proteins are produced from the dec-1 eggshell gene in drosophila by alternative RNA splicing and proteolytic cleavage events. Dev. Biol. 142:1-12.

WiLliams, M. P. 1994. The structure and function of proline-rich regions in proteins. Biochem. J. 297:249-260. 